\title{
Future directions for CHP plants using biomass and waste - adding production of vehicle fuels
}

\author{
Chaudhary Awais Salman ${ }^{1}$, Erik Dahlquist ${ }^{1 .}{ }^{*}$, Eva Thorin ${ }^{l}$, Konstantinos Kyprianidis ${ }^{1}$, \\ Anders Avelin ${ }^{I}$
}

${ }^{1}$ School of Business, Society and Engineering, Mälardalen University, PO Box 883, SE-721 23

Västerås, Sweden

*Corresponding author: erik.dahlquist@mdh.se

\begin{abstract}
In Northern Europe, the production of many biobased CHP plants is getting affected due to the enormous expansion of wind and solar power. In addition, heat demand varies throughout the year, and existing CHP plants show less technical performance and suffer economically. By integrating the existing CHP plants with other processes for the production of chemicals, they can be operated more hours, provide operational and production flexibility and thus increase efficiency and profitability. In this paper, we look at a possible solution by converting an existing CHP plant into integrated biorefinery by retrofitting pyrolysis and gasification process. Pyrolysis is retrofitted in an existed CHP plant. Bio-oil obtained from pyrolysis is upgraded to vehicle grade biofuels. Gasification process located upfront of CHP plant provides the hydrogen required for upgradation of biofuel. The results show that a pyrolysis plant with 18 ton/h feed handling capacity ( $90 \mathrm{MWth})$, when integrated with gasification for hydrogen requirement and CHP plant for heat can produce $5.2 \mathrm{ton} / \mathrm{h}$ of gasoline/diesel grade biofuels. The system integration gives positive economic benefits too but the annual operating hours can impact economic performance.
\end{abstract}

\section{Introduction}

In Northern Europe, there are many biomass and waste-based combined heat and power (CHP) plants to fulfill the heat and electricity demand. Since the enormous expansion of wind and solar power especially in Germany, Denmark, and Sweden, we see strong competition between these and the thermal power of all kind [1], [2]. The wind and solar power cannot be controlled and thus have priority over these CHP plants to the electric grid. Furthermore, the variation in heat demand throughout the year also forced these CHP plants to operate on part load. Part load operation of CHP plant with too few operational hours not only make the economic performance worse but also decrease the overall process energy efficiency [3]. By integrating the CHP plants with thermochemical processes for the production of biofuels/chemicals the integrated processes can be operated more hours, give high energy return and may also increase the profitability [1], [2].

Both gasification and pyrolysis processes can treat biomass and waste into a variety of biofuels in standalone processes. However, these processes are carried out at a high temperature and require heat at various unit operations. The heat required has to be produced onsite for standalone gasification and pyrolysis process. Existing CHP plants can provide the required heat for these thermochemical processes during off-peak hours and 
increase its overall operating capacity throughout the year. In this paper, we look at a novel solution to integrate pyrolysis and gasification including gas upgrading with existing CHP plants. Three criteria have been selected to design the integrated processes. (1) All the heat required to run the pyrolysis and gasification processes should be produced and provided within the whole integrated system. (2) The capacity of integrated plants is selected in such a way that integrated processes will not affect the heat and power production in existing CHP plants. (3) The hydrogen required for the upgradation of bio-oil from pyrolysis is produced in the upfront gasification system.

\section{Process integration concept}

The process integration concept is presented in Fig 1. Pyrolysis is retrofitted with a boiler of existing CHP plant [4]. The pyrolysis takes heat coming from the hot sand from the combustor. Vapors obtained from the pyrolysis are condensed to bio-oil while noncondensable gases are sent back to the boiler. The biochar along with sand is also circulated back to the boiler of existing CHP plant. The bio-oil is a thick brown liquid and composed of complex oxygenated hydrocarbons with water in it. Bio-oil can be upgraded via hydrotreating to vehicle fuels. In this process, oxygen in bio-oil is removed as a water and carbon dioxide by reacting it with hydrogen at high pressure and moderate temperature. Amount of hydrogen required for hydrotreating is usually $4-5 \mathrm{wt} . \%$ of the total bio-oil weight. The required hydrogen can be purchased or produced onsite by the steam reforming of off-gas from hydrotreater but this gas is usually not enough so natural gas from the grid is required to produce the hydrogen. The purchasing of hydrogen or natural gas from the grid takes a toll on the economic performance of the whole process [5]. The upfront gasifier is designed to produce the required hydrogen. Gasification produces the required hydrogen for the upgradation of bio-oil. Steam is used as an oxidizing agent and imported from existing CHP plant. The syngas obtained from the gasifier is upgraded to hydrogen by membrane separation with liquid absorbent [7].

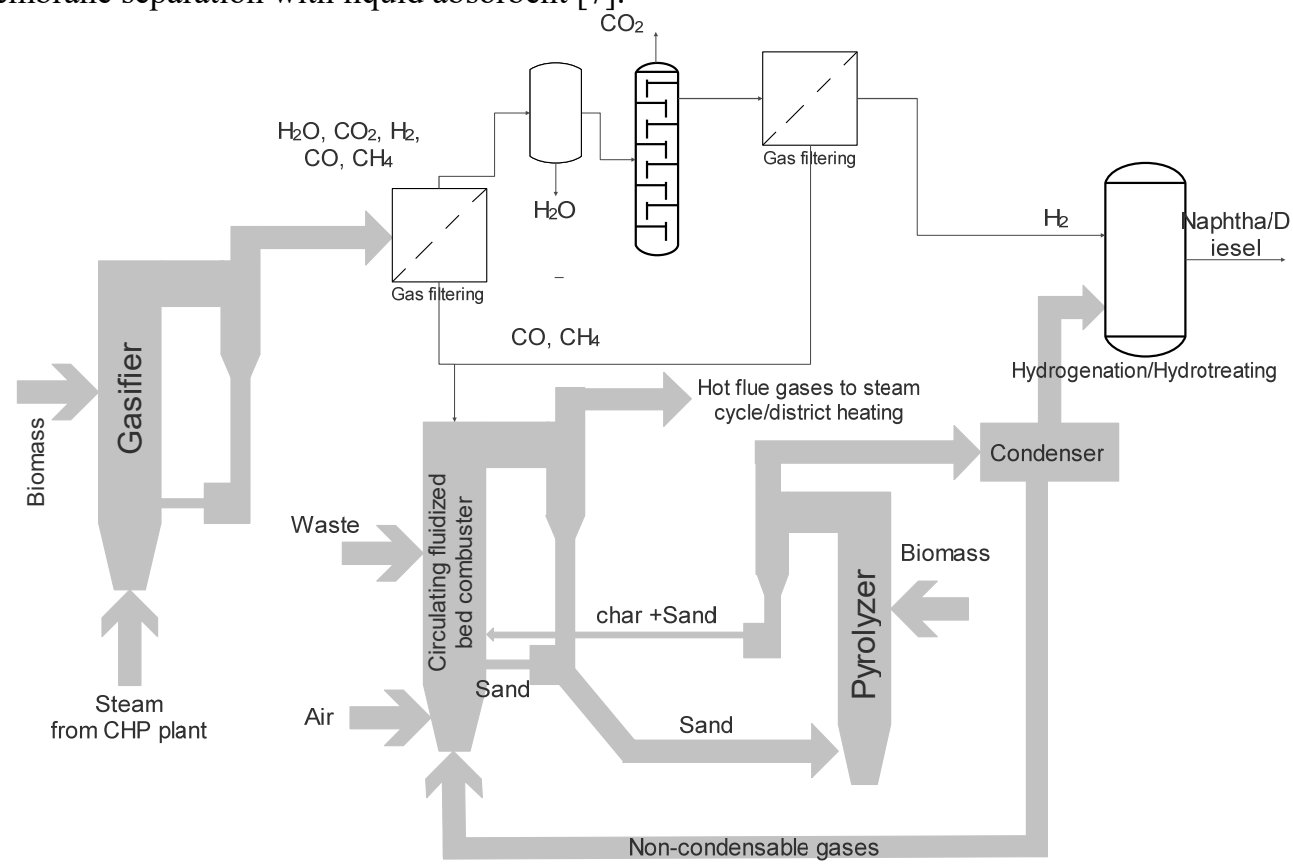

Fig 1: Process scheme with pyrolysis integrated with existing CHP combustor and gasifier integration at the upfront of CHP plant (Unit operations with grey part are simulated in Aspen plus) 


\section{Process modeling and simulation}

A circulating fluidized bed (CFB) boiler located in Malarenergi CHP plant, Västerås, Sweden is considered as a base existing process. The boiler operates on refuse-derived fuel and has a capacity of $180 \mathrm{MWth}$. The studied system (Figure 1) was simulated using Aspen plus. The existing CHP plant was previously modeled and simulated by authors [1]. Modelling and simulation of pyrolysis and gasification processes were also developed by authors previously [1], [2], [8], [9]. The bio-oil upgradation methodology has been adopted by Dutta et al. [6]. The hydrogen required for hydrotreating of bio-oil was imported from the gasification process upfront to CHP plant.

In the reference CHP plant, the steam enters the turbine at $470{ }^{\circ} \mathrm{C}$ and 74 bar. For the mass integration, steam was extracted at the second stage of the steam turbine at $250{ }^{\circ} \mathrm{C}$ and $4 \mathrm{bar}$ to use as an oxidizing agent in the gasifier. The char and unreacted gases in gasifier were combusted in the existing boiler as additional fuel. Similarly, the biochar and noncondensable gases from pyrolysis integrated with CFB boiler are also combusted as additional fuel in the existing boiler. For heat integration, the pinch temperature of $5 \mathrm{~K}$ has been considered.

\section{Results}

\section{Technical performance:}

For integration case, it was assumed that half the capacity of the boiler can be pyrolyzed for liquid fuels, i.e., approximately $90 \mathrm{MW}$. The feed selected for the thermochemical conversion was either wood pellets or waste with a high heating value of $18 \mathrm{MJ} / \mathrm{kg}$. This implies that the pyrolysis process needs $18 \mathrm{ton} / \mathrm{h}(5 \mathrm{~kg} / \mathrm{s})$ of biomass feed. The amount of bio-oil produced was $12.4 \mathrm{ton} / \mathrm{h}$ and require $0.6 \mathrm{ton} / \mathrm{h}$ of hydrogen for hydrotreating. Gasification of wood pellets produces the required hydrogen. From the simulation, it has been estimated that $12.6 \mathrm{ton} / \mathrm{h}(3.5 \mathrm{~kg} / \mathrm{s})$ of feed is required in the gasification process. The steam required to gasify biomass has to be imported from an existing boiler in such a manner that extraction of steam will not disturb the required heat demand. Hence steam to biomass ratio of 0.6/1 was found optimum for the studied process. $7.5 \mathrm{ton} / \mathrm{h}(2.1 \mathrm{~kg} / \mathrm{s})$ of the steam needs to be imported from existing CHP plant. The upgradation of bio-oil produced $2.6 \mathrm{ton} / \mathrm{h}$ of biofuel with naphtha range hydrocarbons and $2.6 \mathrm{ton} / \mathrm{h}$ with diesel range hydrocarbons. The integrated process also produces approximately $39 \mathrm{MW}$ excess heat from the burning of additional fuel in the CFB boiler containing biochar, noncondensable gases from pyrolysis, and syngas from gasification after separation of hydrogen. It also implies that the boiler needs less amount of fuel to run on full load when integrated with pyrolysis/gasification (46 ton/h instead of 60 ton $/ \mathrm{h}$ ).

It has also been observed that steam to biomass ratio has a big effect on the volume fraction of synthesis gas and subsequently the amount of hydrogen produced as a result. The amount of biomass to produce the required hydrogen varied by changing the steam to biomass ratio (figure 2). 


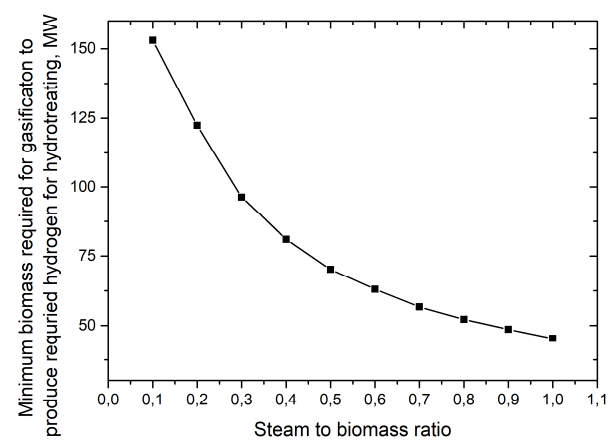

Fig 2: Effect of steam to biomass ratio on the minimum gasification capacity requirement to produce the hydrogen needed in hydrotreating

As shown by the results that the demand for hydrogen is $(0.6 \mathrm{ton} / \mathrm{h})$, i.e. $600 \mathrm{~kg} / \mathrm{h}$ equivalent to $300 \mathrm{kmol} \mathrm{H}_{2} / \mathrm{h}$. We can go backward and look at two different alternatives. In alternative 1, we assume a water gas shift reactor (WGS) and alternative 2 with a membrane with a thin layer of Palladium and Tantal on a porous ceramic tube. In the WGS reactor, we assume $82 \%$ conversion of methane [10] and $96 \%$ conversion of CO [11]. For membrane separation process to produce hydrogen, we assume that $90 \%$ of the hydrogen is passing the membrane with quality of $>99 \% \mathrm{H}_{2}$, and we can also neglect permeation of other components. In Table 1 we see the gas components as $\mathrm{kmol} / \mathrm{h}$ from the gasifier for both alternatives, i.e., (1). After the WGS reaction and (2). After the membrane filtration.

Table 1: Syngas composition as $\mathrm{kmol} / \mathrm{h}$ neglecting the nitrogen and steam $(\mathrm{kmol} / \mathrm{h})$

\begin{tabular}{|c|c|c|c|c|c|}
\hline & $\mathrm{CO}_{2}$ & $\mathrm{CO}$ & $\mathrm{CH}_{4}$ & $\mathrm{H}_{2}$ & $\mathrm{H}_{2} \mathrm{O}$ \\
\hline After gasifier & 190.3 & 135.7 & 53.9 & 28.6 & 247.8 \\
\hline 1. After WGS reactor & 364.7 & 5.4 & 9.7 & 335.6 & 29.2 \\
\hline $\begin{array}{ll}\text { 2. After membrane } \\
\text { filtration }\end{array}$ & & & & & \\
\hline Permeate & & & & 302 & \\
\hline Reject & 364.7 & 5.4 & $9-7$ & 33.6 & 29.2 \\
\hline
\end{tabular}

$300 \mathrm{kmol} \mathrm{H} / \mathrm{h}$ correspond to $6720 \mathrm{~nm}^{3} \mathrm{H}_{2} / \mathrm{h}$. According to [12] the permeate flux through the Palladium membrane is $30.5 \mathrm{~m}^{3} / \mathrm{m}^{2} . \mathrm{h}$ at $\mathrm{dP}=10$ bar, and twice as much at 20 bar $\mathrm{dP}$ (pressure difference over the membrane). If we assume 10 bar $\mathrm{dP}$ the membrane surface area would be $220 \mathrm{~m}^{2}$.

\section{Economic assessment:}

The cost for the Pd-coated membrane is estimated by [12] to be $574-765 € / \mathrm{m} 2$. For 220 $\mathrm{m} 2$ the installation cost for membrane with modules would be $126-168 \mathrm{k} €$. To this, we need a gas compressor for the flow $14700 \mathrm{~nm} 3 / \mathrm{h}$ increasing the pressure to 10 bar [13]. With a two-stage gas compressor, the power demand would be some 1700-1850 hp. The average cost for a complete gas compressor station in the US is $1712 \$ / \mathrm{hp}$ according to Zhao and Rui [14]. For our demand, the compressor cost estimates to approximately $2.57-$ 2.79 M€. We also need to include a heat exchanger for gas cooling and reheating to some $300{ }^{\circ} \mathrm{C}$. According to Harvey et al. [15], gas-gas heat exchangers have an average cost around or $430-540 \$ / \mathrm{kW}$. We have a gas flow out of the reactor around $657 \mathrm{kmol} / \mathrm{h}$ or $14700 \mathrm{~nm}^{3} / \mathrm{h}$ without nitrogen or some $23000 \mathrm{~nm}^{3} / \mathrm{h}$ with nitrogen. If we assume, $400{ }^{\circ} \mathrm{C}$ cooling demand amounts to $3675-5750 \mathrm{~kW}$. This means the cost for the heat exchanger 
would be around $1.42-2.74$ Million $€$. For the actual gasifier plant, we already have an estimate for a $90 \mathrm{MW}$ plant at $50 \mathrm{M} €$ including ceramic filter and condenser earlier [7]. In our, the direct demand for production of the hydrogen needed is approximately $25 \mathrm{MW}$ ( HHV in the produced gas), or $38 \mathrm{MW}$ with $25 \%$ combusted an input of $33 \mathrm{MW}$ fuel, with some margin $38 \mathrm{MW}$ for the gasifier, or $24.7 \mathrm{M} €$. There will be additional costs for buildings and installations connecting the gasifier, gas upgrading and rebuild of G-valve to become the pyrolyzer. A rough estimate would be around $10 \mathrm{M} €$. For the upgradation of bio-oil to liquid gasoline and diesel grade biofuels, the capital cost is estimated from Jones et al. [5]. The capital cost for hydrotreating and hydrocracking of bio-oil is estimated as 18$23 \mathrm{M} €$. Total capital expenses used as in this study is estimated as a summation of both plants i.e., $68 \mathrm{M} €$. With the annuity factor of 0.081 , we get an annual capital cost of 5.5 $\mathrm{M} € / \mathrm{y}$. Table 2 describes the production costs with biomass and waste as an input fuel. We neglected the cost of the existing CHP plant. We assume that the plant should operate 7000 hours in an annual year. However, during the winter the demand for heat may be quite high, and the focus will be on delivery of heat to consumers. Then the operational hours can be expected to be lower for fuel production. We thus make also a calculation for $5000 \mathrm{~h}$ operations per year reported above. For less operating hours, we used the same capital investment cost, but electric power and staff costs will be less. Similarly, the consumption of biomass also affects.

Table 2: Operating and production costs for liquid fuel

\begin{tabular}{|l|l|l|}
\hline \multicolumn{2}{|l|}{ Gasifier + (Pyrolysis-CHP) } \\
\hline Annual operating hours, h & $\mathbf{7 0 0 0}$ & $\mathbf{5 0 0 0}$ \\
\hline Capital costs gasification plant, M€ & 45 & 45 \\
\hline Capital costs hydrotreating and hydrocracking of bio-oil, M€ & 23 & 23 \\
\hline Total capital costs, M€ & 68 & 68 \\
\hline Annualized capital cost (0.08 annuity), M€/y & 5.5 & 5.5 \\
\hline Operating costs & 0.37 & 0.27 \\
\hline Electricity costs ((1.27-1.38 MW) @ 40€/MWh, k€/y & 0.5 & 0.5 \\
\hline Membrane replacement, k€/y & 1 & 0.7 \\
\hline Staff costs, M€/y & 7.37 & 6,67 \\
\hline Operating costs, M $€ / y$ & -3.2 \\
\hline Fuel costs & 14.9 & -2.8 \\
\hline (1) Waste $(-12 € / M W h), M € / y$ & 10.71 \\
\hline (2) Biomass $(14 € / \mathrm{MWh}), \mathrm{M} € / \mathrm{y}$ & 4.17 \\
\hline Total operating costs with waste as fuel, M€/y & 22.27 & 17.52 \\
\hline Total operating costs with biomass as fuel, M€/y & 0.15 \\
\hline Production costs & 0.12 \\
\hline Production costs $(€ / \mathrm{kg})$ liquid fuel with waste as feed & 0.63 \\
\hline Production costs $(€ / \mathrm{kg})$ liquid fuel with biomass as feed & 0.63 \\
\hline
\end{tabular}

The production costs with less operating hours produced fuel at higher production costs. This also shows that any plant which operates at less capacity than designed gives less economic benefits. Further economic indicators such as net present value and payback period and internal rate of return have also been estimated by following the procedure described in [16].

Table 3: Economic indicators of integrated process

\begin{tabular}{|l|c|c|c|c|}
\hline Economic indicators & \multicolumn{2}{|c|}{ With biomass as fuel } & \multicolumn{2}{c|}{ With waste as fuel } \\
\hline & $7000 \mathrm{~h}$ & $5000 \mathrm{~h}$ & $7000 \mathrm{~h}$ & $5000 \mathrm{~h}$ \\
\hline Internal rate of return, \% & 9 & 5 & 10 & 6 \\
\hline Payback period, years & 7.1 & 10 & 6.1 & 9 \\
\hline Net present value, M€ & 86 & 17 & 118 & 20 \\
\hline
\end{tabular}




\section{Conclusion and further work}

The production of district heat is always a primary product in an existing CHP plant however, the production of power mainly depends on the price fluctuation of electricity along with demand. With higher prices of electricity, CHP plant can produce more power. However, with the increased competition of power from alternative renewable resources, it would be feasible to produce other products through the conversion of CHP plants into waste-based integrated biorefineries through the integration of other thermochemical processes. CHP-pyrolysis integration can produce liquid fuel all the year-round i.e., during a normal winter it could produce liquid fuel with $7000 \mathrm{~h} / \mathrm{y}$, but during harsh winter significantly less i.e., around $5000 \mathrm{~h} / \mathrm{y}$.

The combination of gasification and pyrolysis system to produce liquid fuel seems feasible both economically and technically, but the complexity increases with such a system. On the other hand, we are also facing future complex energy scenarios. With the multiple renewable energy resources present to meet the energy demand there is a requirement to find complex solutions to implement for different regions and situations. To reduce the complexity of whole system integration, we can produce bio-oil from pyrolysis at one facility and then upgrade it at another refinery as the transportation of liquid bio-oil is easier. Another option to decrease the complexity of integration is to produce liquid biofuels CHP plant integrated with gasification with Fischer-Tropsch (FT) fuels reactor.

Acknowledgments: This work was supported by the Swedish Knowledge Foundation (20120276) (KKS) and the co-production partners within the framework Future Energy: ABB, Castellum and the VEMM group (VafabMiljö, Eskilstuna Energi och Miljö, and Mälarenergi).

\section{References}

[1] C. A. Salman, M. Naqvi, E. Thorin, and J. Yan, Energy Convers. Manag., 152, May, (2017).

[2] C. A. Salman, M. Naqvi, E. Thorin, and J. Yan, Appl. Energy, 226, January, (2018).

[3] E. Sermyagina, J. Saari, J. Kaikko, and E. Vakkilainen, Appl. Energy, 183, (2016).

[4] H. Hadera, University of Iceland (Master thesis), 2011.

[5] S. Jones et al., PNNL Rep., PNNL-23053, (2013).

[6] A. Dutta et al., March 2015, (2015).

[7] E. Dahlquist, M. Naqvi, E. Thorin, J. Yan, K. Kyprianidis, and P. Hartwell, Appl. Energy, 204, (2017).

[8] C. A. Salman, S. Schwede, E. Thorin, and J. Yan, Appl. Energy, 204, (2017).

[9] C. A. Salman, S. Schwede, M. Naqvi, E. Thorin, and J. Yan, Energy Procedia, 158, (2019).

[10] Y. Lv, X. Yu, S.-T. Tu, J. Yan, and E. Dahlquist, J. Memb. Sci., 362, 1-2, (2010).

[11] F. T. Report et al., August, (2008).

[12] P. K. T. Liu and A. Anderson, Annu. Rep., (2007).

[13] D. C. and M. F. J. Torkelson, N. Ye, Z. Li, Tech Rep., (2008).

[14] Y. Zhao and Z. Rui, Int. J. Oil, Gas Coal Technol., 8, 1, (2014).

[15] R. Hackl and S. Harvey, Hackl-2013, (2013).

[16] J. Turton, Richard; C. Bailie, Richard; B. Whiting, Wallace; A. Shaeiwitz, 2009. 